\title{
CARDIAC OUTPUT DETERMINATION IN THE OPERATING ROOM: A MICROTECHNIQUE
}

David Allan, m B, Ch.B., A W. Conn, m D, B.sc.(med.), f.R CP (c), and C. I. JUNKIN, M B ${ }^{1}$

THERE HAS BEEN a need for a simple method of cardiac output determination under operating room conditions. A practical method has been evolved. It is an area dye dilution technique after Hamilton (1), employing "Coomassie Blue RL" $(\mathrm{AY}-58112)^{2}$, and applying the Forward-Triangle Formula of Hetzel (2).

\section{DESCRIPTION}

The apparatus used is a Sanborn Oximeter Adapter Box Model 461-160 which couples a Waters Oximeter Control Box Model X70, insulated and modified for dye estimations, to a Sanborn Low Level Preamplifier Model 150-1500, Modification $\mathrm{A}$ The following control settings are applicable:

Waters Oximeter Control Box Model X70 (Modıfied)

1. Sensitivity at H.S.

2. Blue Dye Sensitivity Control at maximum

Sanborn Low Level Preamplifier Model 150-1500 (Mod. A)

I. Attenuation X I

2. Sensitivity adjusted so that a calibration signal of $40 \mathrm{~m} \mu$ gives a deflection of $0.7 \mathrm{~cm}$.

Hum and stray potentials are negligible.

Automation can be accomplished successfully with a constant flow system such as the Colson Model 1055 for withdrawal, and two compressed air-firing systems with split-second staggered timing for the injection of dye and flushing solution, interconnected through an appropriate coupler to the remote marker position of the Sanborn system.

As this method is primarily designed for operating room use, a Waters cuvette is employed, but there is no contra-indication to an earpiece oximeter.

The dye selected was Coomassie Blue RL for the following reasons. (i) In the doses employed even on repeated application, there is no clinically observed staining of the patient, in sharp contrast to Evans Blue. (ii) It has a reasonably fast excretion time of four hours. Cardio-green is much more rapidly excreted, but it is open to question whether or not it circulates at least once in toto, before leaving the circulation. Therefore it cannot be used for output determination.

Owing to the purity of the dye curves obtained it is not found necessary to rigidly apply a dose weight relationship. Thus a $1.0 \mathrm{ml}$. syringe is calibrated in

1From the Department of Anaesthesia, Hospital for Sick Children and University of Toronto, Toronto.

2Supplied by Ayesșt, McKenna \& Harrison, Lumited, Montreal, P.Q. 
only three positions, $0.3 \mathrm{ml}$, $0.6 \mathrm{ml}$, and $1.0 \mathrm{ml}$. For example a $6 \mathrm{mg}$. dose is satisfactory for a patient weighing up to $30 \mathrm{~kg}$.

\section{Calibration of the Peak Concentration Using Three Standard Solutions}

1. Using a calibrated syringe approximately $20 \mathrm{cc}$. of the patient's blood is placed into each of three bottles containing mixing beads.

2. Then, 20 Landau units of heparin are added.

3. Then, 20, 40, and 60 Landau units of dye are added to the bottles successively.

4. The bottles are vacuumed by withdrawing the air through the rubber stoppers with a syringe. This prevents changes in $\mathrm{O}_{2}$ saturation.

This interrelationship of three known quantities of dye to known quantities of blood produces three standards of $20 \mathrm{mg} . / \mathrm{L}, 40 \mathrm{mg}$./L., and $60 \mathrm{mg} / \mathrm{L}$. approximately On passing the samples through the cuvette, three linear deflections are obtained.

\section{Calculations}

The "forward triangle" of Hetzel is the initial portion of the dye curve that is delineated by the peak concentration $\left(C_{p}\right)$ and the build up time $\left(T_{B}\right)$ (see Fig. 1).

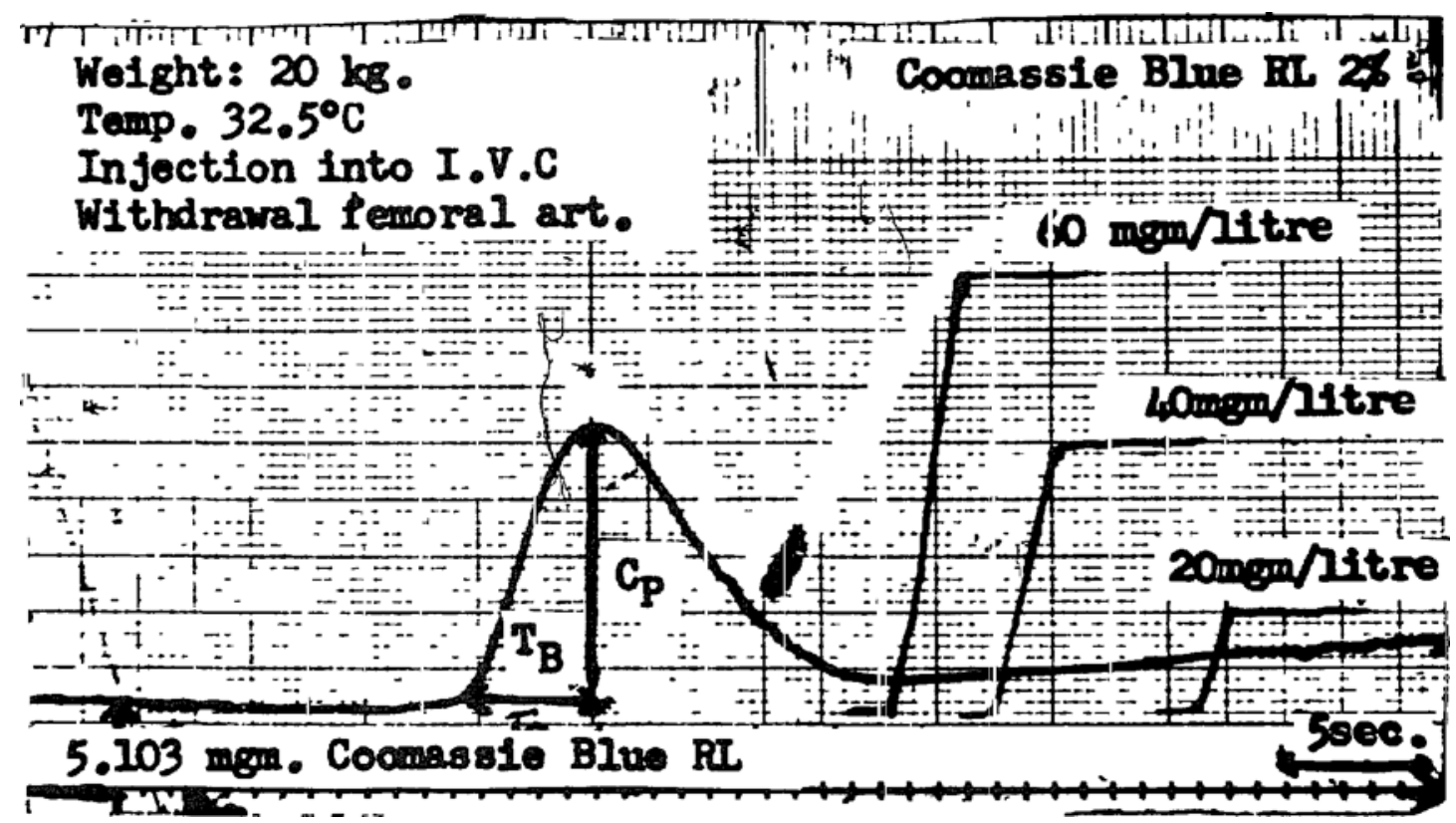

Figuae 1. Dye curve.

Forward Triangle Formula:

$$
Q=\frac{2 K 60 I}{\mathrm{~T}_{\mathrm{B}} \mathrm{C}_{\mathrm{P}}} \quad \text { where } \quad \begin{aligned}
Q & =\text { cardiac output }(\mathrm{L} / \mathrm{mun}) \\
K & =\text { constant of proportionality } 1037 \text { for central injection }) \\
I & =\text { total amount o injected incicator (mg) } \\
\mathrm{T}_{B} & =\text { building up time (sec. }) \\
\mathrm{C}_{P} & =\text { peak concentration (ming } / 1)
\end{aligned}
$$


Also, on repeated estimations on the same patient, using a constant dose of dye:

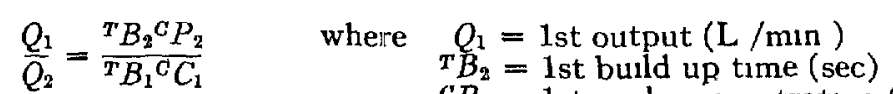

$$
\begin{aligned}
& c P_{1}=1 \text { st peak concentration }(\mathrm{mg} / \mathrm{L}) \\
& \left.Q_{2}=2 \text { nd output ( } \mathrm{L} / \mathrm{min}\right) \\
& r_{B_{2}}=\text { 2nd buld up time (sec) } \\
& { }^{c} P_{\mathrm{a}}=2 \text { nd peak concentration }(\mathrm{mg} . / \mathrm{L} \text {.) }
\end{aligned}
$$

Therefore, the effect of variable factors, such as anaesthetic agents, on cardiac output can be readily assessed and compared.

\section{SOURCES OF ERROR}

1. If the oxygen saturation of the patient varies during withdrawal, the base line wanders so that no quantitative estımation can be made.

2. A cardrac catheter of less than size 7 in the arterial side will not consistently give a good withdrawal, especially if the Colson Constant Flow System is used

3. It is preferable to use central sites and use the figure 0.37 as the constant of proportionality.

4. As this is a microtechnique, care must be exercised in measuring dye doses and dilution of the standards.

5. Practice is necessary to ensure exact timing unless an automated system is used in firng dye and flushing solution.

6. The volume of the arterial catheter in relation to the time-withdrawal cycle must be considered in assessing the efficacy of the curve.

7. This method is not applicable when peripheral or central shunts or regurgitation are present.

\section{ConCLusion}

A microtechnique for the estimation of cardiac output has been evolved. It is accurate and functional for operating room use.

To a dye dilution area method a simplified formula is applied resulting in cardiac output determination being readily available.

\section{ACKNOWLEDGMENTS}

The authors wish to thank W. T. Mustard, F R C S.(C), Senior Cardiovascular Surgeon, Hospital for Sick Children, Toronto, and his staff for their co-operation during this study.

They also wish to acknowledge the help, guidance, and encouragement given by R D. Rowe, M.B., Cardiologist, Hospital for Sick Children, Toronto.

\section{RÉSUMÉ}

La micro-technique pour la determinations du "output" cardiaque a été mise en évidence. Elle est exacte et appropriée pour la salle d'opération. Une méthode 
simplufiée de colorimétrie fut employée. Elle nous a permit d'obtenir immédiatement la determination de l'output cardiaque.

\section{REFERENCES}

1. Hammton, W. F., Moore, J. W., Kinsman, J. M., \& Spurinng, R. R. Am. J. Physiol 84: 338 (1928).

2. Hetzel, P S., Swan, H. J C., Ramifez de Arellano, A A.; \& Wood, E. H. J. Appl. Physiol 13. 92 (1958) 